\title{
A Content Analysis of Published Articles in Sport Mont from 2016 to 2017
}

\author{
Miomir Maros \\ University of Montenegro, Faculty for Sport and Physical Education, Niksic, Montenegro
}

\begin{abstract}
A B S T R A C T
Sport Mont is a scientific journal that exists for 14 years and has so far released about 1000 scientific papers. The papers are from various fields of sports science - biomechanics, physiology, sports medicine, anthropology, methodology and other areas of sports. In this paper, we classified works by fields, method of address analysis and found that the most numerous works from the physiology of sports, which are the most cited and best quoted in scientific databases. We have also established that the published works had themes - the most up-to-date tendencies in sports science. These research can be useful for further theoretical research, as well as for theoreticians. The authors of the works are researchers from all over the world, as well as the editorial board. The Sport Mont includes works from exact disciplines, primarily physiology of sports, as well as from social sciences, thus achieving a synergistic effect. The highly cited topics in the field of physiology of sports are raised by the work of social sciences. These topics when they find themselves in the magazine with a social label increase their own visibility.
\end{abstract}

Key words: Science, Sport Mont, Sport, Medicine, Montenegro

\section{Uvod}

Sport Mont Journal je osnovan 2003. godine i ima prilično dugu tradiciju. Do danas je objavljeno blizu 1000 naučnih radova istraživanja sa svih kontinenata. To su uglavnom radovi predstavljeni na naučnim konferencijama Crnogorske sportske akademije, koji se tradicionalno održavaju svake godine krajem marta ili početkom aprila. U 2016. godini, sajt časopisa je redi- zajniran i napravljena je prekretnica, iz koje će časopis nastaviti da raste i razvija se brže. Naime, uputstva za autore, dizajn i struktura su reformisani i objavljivanje časopisa je tri puta godišnje (u februaru, junu i oktobru) sa po 10 radova. Urednički odbor je ojačan, što će se dešavati i ubuduće. Danas je Sport Mont Journal indeksiran u dvadeset dvije međunarodne baze podataka, i mora se naglasiti da u ovom trenutku prolazi kroz proces procjene u Scopusu $\mathrm{i}$ Web of Science bazi podataka. Za

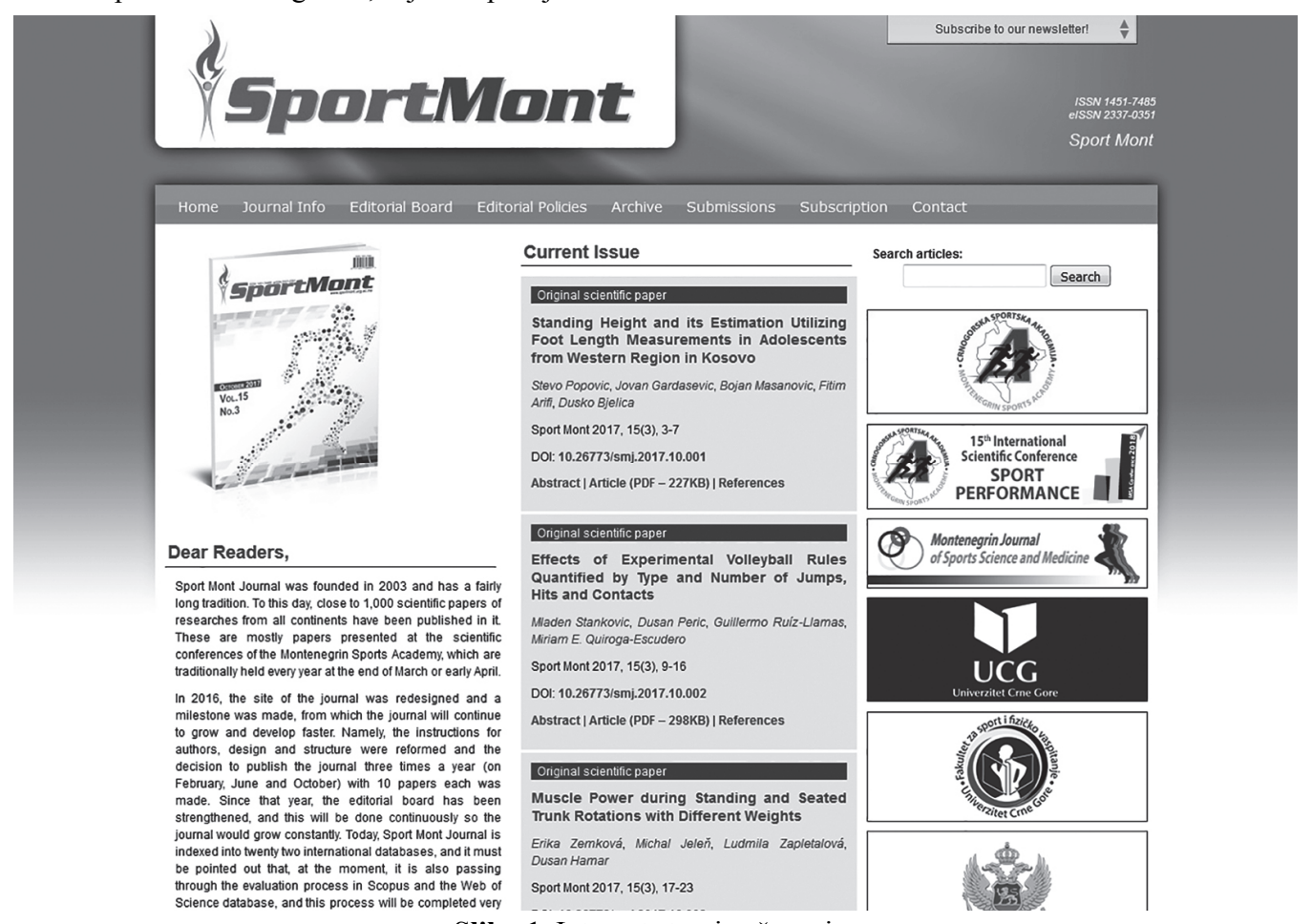

Slika 1. Internet stranica časopisa 
oktobarsko izdanje 2017. pripremljena je nova naslovna stranica sa novim logotipom. Po prvi put, svaki naučni rad ima prepoznatljivi DOI broj. Sad časopis ima dva glavna urednika, zajedno sa profesorom Duškom Bjelicom, koji od samog početka obavlja ovu funkciju, promovisan je profesor Zoran Milošević. Značajne promjene su učinjene na web stranici Sport Mont Journala. Poslednjih 10 objavljenih radova, koje se do sada mogu naći samo u arhivi sajta, od sada će biti sadržane na početnoj stranici sajta. Takođe, uvedena je i statistika časopisa, gdje se mogu vidjeti najnoviji statistički indikatori. Takođe je redizajniran sistem preuzimanja dokumenata u PDF formatu, uvedeni su bar kodovi za svaki članak, podaci o citiranju i broj preuzetih radova. Takođe, pod svakim radom uveden je diskusioni forum, gdje čitaoci mogu objaviti svoje komentare i sugestije koje mogu poboljšati kvalitet časopisa. „Sport Mont“ objedinio je autore i radove iz oblasti prirodnih i društvenih nauka koji su time dali svoj doprinos razvoju nauke o sportu, baveći se raznovrsnim i zanimljivim temama.

\section{Metod}

Analiza sadržaja je metoda često prisutna u medijskim istraživanjima koja kvalitativno i kvantitativno sistematizuje prvenstveno novinarske oblike komunikacije, pa se zbog otkrivanja frekvencija, odnosno učestalosti tema i poruka prilikom obrade podataka, koriste statističke metode, a u jednostavnijem obliku zbrajanje i deskripcija. Pod analizom sadržaja, dakle, podrazumijevamo sistematsko prebrojavanje, procenjivanje, interpretiranje i analizu materijalnih formi komunikacije. Jedinica u procesu analize sadržaja je, najjednostavnije rečeno, specifičan element ili karakteristika u datoj komunikaciji koji je predmet ispitivanja, brojanja ili procjenjivanja. Najbazičniji element komunikacije je npr. riječ. Tako izabrana riječ može biti jedinica analize neke komunikacije. Analitička jedinica često može biti ajtem tj. fizički nosilac komunikacije u cjelini, npr. naslovi novina ili naučnih časopisa. Jedinica analize sadržaja u ovom radu su naslovi naučnih radova objavljenih u „Sport Mont“-u, od februara 2016. do oktobra 2017, na engleskom jeziku. U tom periodu objavljeno je 60 radova u 6 izdanja časopisa. Radovi su klasifikovani po oblastima sportskih nauka - na biomehaniku, fiziologiju, sportsku medicinu, antropologiju, metodologiju i ostale radove.

\section{Rezultati}

U „Montenegrin Journal of Sports Science and Medicine“ zastupljeni su radovi iz metodike i pedagogije, istraživanja $u$ sportu i sociopsihologije sporta, menadžmenta, te iz oblasti antropomotorike i antropometrije - "Znanje studenata fizičkog vaspitanja o sportskoj ishrani“ (Vasiljević, Bjelica, Kezunović \& Gardašević, 2016), ,,Model reklamnog komuniciranja u sportu“ (Popović \& Milašinović, 2016), „Istorijski razvoj skijanja sa posebnim osvrtom na Crnu Goru“ (Milašinović \& Popović, 2016), „Rangiranje rezultata postignutih u biomotornim i specifičnim motoričkim vještinama kod rukometaša i kadeta koji nijesu atletičari“ (Muratović \& Bojanić, 2016), „Upoređivanje dvije metode interpolacije na centar za rezimiranje podataka o masovnoj brzini““ (Ödek, 2016), „Metode za vrednovanje nekih psihomotornih sposobnosti“ (Krivokapić \& Tanase, 2016), „Nivo transformacije motoričkih vještina odbojkašica pod uticajem trenera" (Mahmutović, Rađo, Talović, Lakota, Alić \& Jelešković, 2016), ,Efekat morfoloških karakteristika i motoričkih sposobnosti na obavljanje tehničkih elemenata u alpskom skijanju“
(Bubanja, Milašinović \& Bojanić, 2016), „Odnosi između antropometrijskih karakteristika i motoričkih sposobnosti plivačica na 50 metara, od 14 - 15 godina“ (Dimitric, Cokorilo \& Bogdanovski, 2016), „Etičke dileme sportskog oglašavanja“ (Bjelica, Gardašević, Vasiljević \& Popović, 2016).

U toku 2017. godine teme su bile: „Razlike u antropometrijskim karakteristikama među elitnim fudbalerima i rukometašima“ (Gušić, Popović, Molnar, Mašanović \& Radaković, 2017), ,Asocijacija sprint performansi sa antropometrijskim parametrima kod mladih fudbalera" (Hyka, Bicoku \& Mysliu, 2017), „Teorije umora u sportu“ (Krivokapić, 2017), „Istorijski razvoj skijanja, studija slučaja na području Durmitora“" (Milašinović, \& Bjelica, 2017), „Percepcije talentovanih srednjoškolskih fudbalera o kriterijumu identifikacije talenata" (Martin \& Sæther, 2017), ,Ispitivanje uticaja nivoa fizičke aktivnosti srednjoškolca na njihovo rješavanje problema" (Kokmaz, Pancar, Alparslan \& Ayan, 2017), ,Žene, sport i bebe - da li je moguće učiniti / imati sve?“ (Kuchar, 2017), „Analiza efikasnosti takmičenja hrvatskih mladih rvača na Evropskom prvenstvu“ (Slacanac, Baic, \& Starcevic, 2017), „Primjena strategije emocionalnog brendiranja u modelu razvoja sportskog brenda na tržišta flaširanih voda“ (Jankovic, 2017), „Efekti eksperimentalnih odbojkaških pravila kvantifikovanih prema vrsti i broju skokova, pogodaka i kontakata“ (Stankovic, Peric, Ruíz-Llamas, \& Quiroga-Escudero, 2017), „Razlike između žena koje se bave pilatesom i aerobikom“ (Radas, Sesar \& Furjan-Mandic, 2017), „Korišćenje istraživanja za Elite Sport u Češkoj Republici“ (Nová, 2017), „Razlike između studenata dva različita studijska programa u procjeni standarda za podučavanje sporta u vodi“ (Oreb, Prlenda \& Oreb, 2017), „Razlike u nekim motornim sposobnostima angažovanih djevojaka i onih koje nijesu uključene u estetske aktivnosti“ ( Cosic Mulahasanovic, Nozinovic Mujanovic, Mujanovic \& Atikovic, 2017) i „Istorijski razvoj olimpijskog pokreta“" (Siljak \& Djurovic, 2017).

Naučni radovi iz biomehanike istražuju tehnike kretanja sportista i rješenja za poboljšanje: "Šestonedeljni period pripreme i njegovi efekti na brzinu kretanja sa fudbalerima ispod 16 godina“ (Gardašević, Bjelica \& Vasiljević, 2016), „Igrači norveške fudbalske akademije - igrači samoprocjene kompetencije, perfekcionizma, ciljne orijentacije i motivacione klime" (Nerland \& Sæther, 2016), „Odnosi između biomehaničkih parametara i statičke moći ruku kod djece sa poremećenom posturom“ (Andrašić, Milić, Cvetković, Ujsasi \& Orlić, 2017) i „Snaga udaranja lopte nakon priprema sa fudbalerima ispod 15 godina“" (Gardašević, Bjelica \& Vasiljević, 2017).

Najbrojnije i vrlo raznovrsne su teme iz fiziologije sporta koja je dio medicine sporta, a proučava organizam i njegove funkcije tokom fizičkih aktivnosti: „Ultra kratkotrajna srčana frekvencija nakon maksimalne vježbe na dvije različite pozicije tela elitnih muških džudista u poređenju sa studentima fakulteta za sport" (Vujkov, Calals \& Drid, 2016), "Uticaj redovnog fizičkog vaspitanja na razvoj motorike djece sa posebnim potrebama" (Bojanić, Ljubojević \& Bubanja, 2016), "Efekti različitih nastavnih planova fizičkog vaspitanja na motoričke vještine kod učenika završnih razreda u osnovnoj školi“ (Ljubojević, Muratović \& Bubanja, 2016), "Efekat treninga funkcionalne snage na pregibač koljena i istezač mišića kod fudbalera" (Rađo, Alić, Bajramović, Jelešković, Ćović, Likić, \& Mekić, 2016), „Uticaj rekreativnog treninga fitness treninga na dinamičku snagu žena“" (Andrašić, Ujsasi, Cvetković, Orlić \& Milić, 2016), „Uticaji treninga u pripremnom periodu na repetitivnu transformaciju snage kod fudbalera kadetskog nivoa" (Gardašević, Bjelica, Vasiljević \& Milašinović, 2016), „Atributi mentalne žilavosti kod nagrađenih badmington igrača juniora“ (Antony \& Antony, 2016), „Procjena i razlike u anaerobnom 
kapacitetu fudbalera koji igraju na različitim pozicijama u timu, koristeći rast test" (Andrašić, Cvetković, Milić, Ujsasi \& Orlić, 2016), „Promjene u ravnoteži utreniranih i neutreniranih starijih osoba u petomjesečnom multikomponentnom programu obuke“ (Cordellat, Lafarga, Monteagudo \& Roldán, 2016), „Poboljšanje ravnoteže kroz vježbe joge“ (Bendo \& Haxholli, 2017), „Uticaj natrijum bikarbonata i natrijum citrata na $\mathrm{pH}$ u krvi, HCO3-, metabolizam laktata i vrijeme do iscrpljenosti““ (Hartono, 2017), „Obim struka kao indikator abdominalne gojaznosti u srednjim godinama“ (Vasiljević, Gardašević, Kezunović \& Bojanić, 2017), „Struktura kognitivnih sposobnosti i vještine spasilaca“ (Ljubojević, Muratović \& Bubanja, 2017), „Odnos između procentualne tjelesne masti i osnovnih motorič- kih sposobnosti kod predškolske djece, od 3-6 godina“ (Musalek, Kokstejn, Papez, Jírovec \& Honsová, 2017), „Eksperimentalni program fizičkog vaspitanja za testiranje uticaja na percepciju vještina“ (Brankovic \& Hadzikadunic, 2017), „Parametri tjelesnih segmenata tokom GS okretanja skijaša rekreativaca“ (Curic, Mujanovic, Huremović \& Mujanovic, 2017), „Snaga mišića tokom stajanja i sjedećih rotacija trupa sa različitim težinama“ (Zemková, Jeleň, Zapletalová \& Hamar, 2017). „Uticaj statičkog istezanja na lagodnost i izokinetičke sile kod fudbalskih igrača“ (Sermaxhaj, Arifi \& Bahtiri, 2017) i „Efekat 8-nedeljnog Džudo kursa mišićne izdržljivosti, fleksibilnosti trupa i eksplozivne snage studenata muškog univerziteta" (Mohammed \& Choi, 2017).
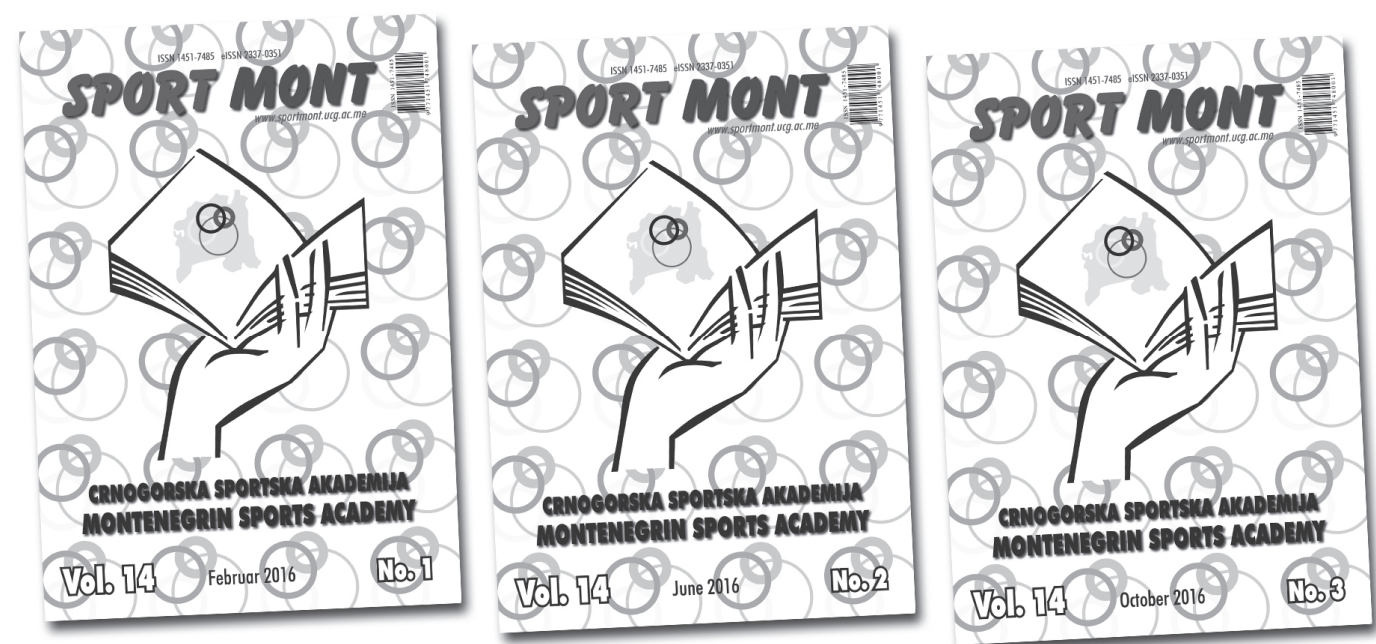

Slika 2. Kolaž naslovnih stranica (2016)

Sportska medicina primjenom nauke i prakse uočava, liječi i rehabilituje, te sprečava povrede izazvane sportom, vježbanjem ili rekreacijom, a teme iz sportske medicine objavljene u „Sport Mont“-u su: „Promjene temperature na stopalu tokom trudnoće uzrokovane habanjem biomehaničkih cipela" (Zvonar, Vavacek \& Cierna, 2016), „Odnos starosti kod menarhe do fi- zičke aktivnosti“ (Peja \& Tase, 2016), „Učestalost deformiteta stopala među studentima fakulteta za sport i fizičko vaspitanje“" (Muratović, Vasiljević, Bojanić \& Ljubojević, 2016) i „Bolni listovi tokom bolova u donjem delu leđa i uticaj gojaznosti na njihovo produženje“ (Kaçuri \& Meka, 2017).
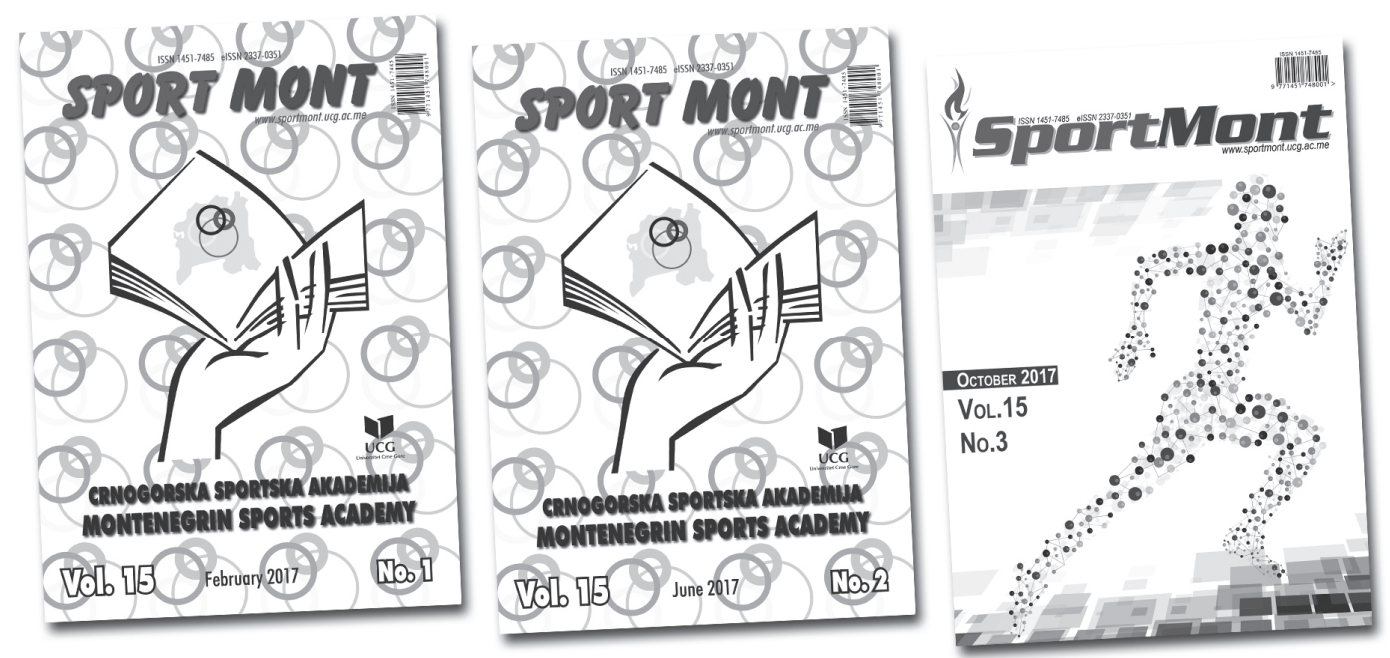

Slika 3. Kolaž naslovnih stranica (2017) 
Antropologija sporta koja proučava veze između određenih disciplina i karakteristika sportista u „Sport Mont“-u je bila zastupljena kroz sljedeće radove: "Važnost sporta u životu učenika i učestalost sportskog učešća među učenicima - rodne razlike“ (Majerič, 2016), „Visina tijela i njegova procjena korišćenjem mjerenja raspona ramena kod muških adolescenata $\mathrm{u}$ južnom regionu u Crnoj Gori“ (Milašinović, Popović, Matić, Gardašević \& Bjelica, 2016), „Korelacija između fizičkih karakteristika i motoričkih veština učenika srednjih škola“ (Milošević, Vuković, Maksimović, \& Matić, 2016), „Planiranje mreže sportskih objekata u kontekstu crnogorske studije slučaja: Herceg-Novi, Podgorica i Danilovgrad“ (Popović, Šestović, Đurović \& Vlahović, 2016), „Visina tijela i njegova procjena korišćenjem mjerenja raspona ramena kod ženskih adolescenata iz južnog regiona u Crnoj Gori“ (Milašinović, Popović, Jakšić, Vasiljević \& Bjelica, 2016), „Rodne razlike u popularnosti i angažman u sportskim aktivnostima među studentima“ (Majerič, 2016), „Visina tijela i njegova procjena korišćenjem mjerenja ruku adolescenata oba roda iz centralnog regiona na Kosovu“ (Arifi, Sermaxhaj, Alaj, Metaj \& Toverlani, 2017) i „Stojeća visina i njena procjena korišćenjem mjerenja dužine stopala kod adolescenata iz zapadnog regiona na Kosovu“ (Popovic, Gardasevic, Masanovic, Arifi \& Bjelica, 2017).

\section{Diskusija}

U ovom radu smo klasifikovali teme iz Sport Mont-a po oblastima, metodom analize naslova i utvrdili da su najbrojniji radovi iz fiziologije sporta (19), sportske metodike i pedagogije, istraživanja u sportu i sociopsihologije sporta, menadžmenta, te iz oblasti antropomotorike i antropometrije (25), a značajno manje iz sportske medicine (4) biomehanike (4) i antropologije

\section{R E F E R E N C E S}

Andrašić, S., Ujsasi, D., Cvetković, M., Orlić, D., \& Milić, Z. (2016). Impact of recreational fitness training program on dynamic strength of women. Sport Mont, 14(2), 25-29.

Andrašić, S., Milić, Z., Cvetković, M., Ujsasi, D., \& Orlić, D. (2017). Relations between biomechanical parameters and static power of arms in children with disturbed posture. Sport Mont, 15(1), 23-26.

Andrašić, S., Cvetković, M., Milić, Z., Ujsasi, D,. \& Orlić, D. (2016). Assessment and differences in anaerobic capacity of football players playing on different positions in the team, using rast test. Sport Mont, 14(3), 21-24.

Antony, V., \& Antony, J. (2016). Mental toughness attributes of junior level medalist badminton players. Sport Mont, 14(3), 3-6.

Arifi, F., Sermaxhaj, S., Alaj, I., Metaj, Z., \& Toverlani, A. (2017). Body Height and Its Estimation Utilizing Arm Span Measurements of both Gender Adolescents from Central Region in Kosovo. Sport Mont, 15(2), 31-34.

Bendo, A., \& Haxholli, K. (2017). The improvent of Equilibrium through yoga exercices. Sport Mont, 15(1), 7-11.

Bjelica, D., Gardašević, J., Vasiljević, I., \& Popović, S. (2016). Ethical dilemmas of sport advertising. Sport Mont, 14(3), 41-43.

Bojanić, D., Ljubojević, M., \& Bubanja, M. (2016). The effect of regular physical education in the transformation motor development of children with special needs. Sport Mont, 14(1), 21-23.

Brankovic, E., \& Hadzikadunic, M. (2017). Physical Education sporta (8). Radovi iz fiziologije sporta su najcitiraniji i najbolje kotirani, pa je to i razlog napredovanja časopisa u smjeru najviših naučnih baza u sportskim naukama. Utvrdili smo i da su objavljeni radovi imali za teme - najsavremenije tendencije u sportskim naukama. Ta istraživanja mogu biti korisna i za dalja teorijska istraživanja, kao i za sportske praktičare.

Časopis "Sport Mont" vezan je za naučnu konferenciju koju Univerzitet Crne Gore i Crnogorska sportska akademija organizuju svake godine početkom aprila, gdje budu ugošćeni i uvaženi respektabilni profesori i naučnici koji rade na volonterskoj osnovi, na recenzijama i uređivanju časopisa. Međunarodna naučna konferencija „Transformacioni procesi u sportu sportska dostignuća“, koja je 14. put organizovana od 30. marta do 2. aprila 2017. u Budvi, okupila je više od 120 učesnika iz 23 države, sa četiri kontinenta. Od 12. do 15. aprila 2018. u Budvi će biti održana 15. Međunarodna naučna konferencija i 14. Kongres Crnogorske sportske akademije.

Da podsjetimo, ,Sport Mont“ sadrži širok spektar tema - od društvenih, preko humanističkih, do prirodnih nauka. Potrebno je napomenuti, da, kao i kod „Montenegrin Journal of Sports Science and Medicine“, uređivački odbor vrlo vješto uklapa radove iz svih oblasti sportskih nauka, što nije lak zadatak zbog velikog raspona i raznovrsnosti tematike. Teme iz oblasti društvenih nauka su mnogo manje citirane u odnosu na teme iz oblasti fiziologije vježbanja, ali sportske nauke koje ih objedinjavaju u jednu naučnu oblast, uspijevaju da naprave dobar spoj ponekad nespojivog, što rezultira međusobnim benefitima. S obzirom da su teme iz oblasti fiziologije vježbanja mnogo citiranije od tema iz oblasti društvenih nauka, one podižu rejting temama iz društvenih nauka, dok, sa druge strane, teme iz npr. fiziologije vježbanja uspijevaju da se nađu u časopisu koji ima društvenu oznaku, pa samim tim postaju vidljivije i izvan usko specijalizovanih časopisa u oblasti fiziologije vježbanja.

Experimental Program to Test the Effect on Perceived Competence. Sport Mont, 15(2), 25-30.

Bubanja, M., Milašinović, R., \& Bojanić, D. (2016). Effect of morphological characteristics and motor abilities on the execution of technical elements in alpine skiing. Sport Mont, 14(3), 11-14.

Cordellat, A., Lafarga, C., Monteagudo, P., \& Roldán, A. (2016). Balance changes in trained and untrained elderly undergoing a five-months multicomponent training program. Sport Mont, 14(3), 25-29.

Cosic Mulahasanovic, I. \& Nozinovic Mujanovic, A., Mujanovic, E. \& Atikovic, A. (2017). Differences in Some Motor Abilities of Girls Engaged and those that are not Engaged with Aesthetic Activities. Sport Mont, 15(3), 47-49. doi: 10.26773/smj.2017.10.009.

Curic, M., Mujanovic, E., Huremović, T., \& Mujanovic, A. (2017). Body Segment Parameters During GS Turn in Recreational Skiers. Sport Mont, 15(2), 35-38.

Dimitric, G., Cokorilo, N., \& Bogdanovski, M. (2016). Relations between anthropometric characteristics and motor abilities of $14-15 \mathrm{U}$ female swimmers on $50 \mathrm{~m}$ result for each technique. Sport Mont, 14(3), 37-40.

Gardašević, J., Bjelica, D., \& Vasiljević, I. (2016). Six-week preparation period and its effects on transformation movement speed with football players under 16. Sport Mont, 14(1), 13-16.

Gardašević, J., Bjelica, D., Vasiljević, I., \& Milašinović, R. (2016). The effects of the training in the preparation period 
on the repetitive strength transformation with cadet level football players. Sport Mont, 14(2), 31-33.

Gardašević, J., Bjelica, D., \& Vasiljević, I. (2017). The Strength of Kicking the Ball after Preparation Period with U15 Football Players. Sport Mont, 15(2), 39-42.

Gušić, M., Popović, S., Molnar, S., Mašanović, B., \& Radaković, M. (2017). Differences in Anthropometric characteristics among elite soccer and handball players. Sport Mont, $15(1), 3-6$.

Hartono, S. (2017). The effects of sodium bicarbonate and sodium citrate on blood $\mathrm{pH}, \mathrm{HCO} 3-$, lactate metabolism and time to exhaustion. Sport Mont, 15(1), 13-16.

Hyka, A., Bicoku, E., \& Mysliu, A. (2017). The association of sprint performance with anthropometric parameters in youth soccer players. Sport Mont, 15(1), 31-33.

Jankovic, M. (2017). Application of Emotional Branding Strategy in the Model Development of Sports Brand of The Bottled Water Market. Sport Mont, 15(2), 49-52.

Kaçuri, D., \& Meka, V. (2017). Sick leaves during the low back pain and influence of obesity on its prolonging. Sport Mont, 15(1), 17-19.

Kokmaz, N., Pancar, S., Alparslan, T., \& Ayan, A. (2017). Examination of the Effect of High School Students Physical Activity Levels on Their Problem Solving Skills. Sport Mont, 15(2), 15-19.

Krivokapić, D., \& Tanase, G. (2016). Methods for evaluation of some psychomotor abilities. Sport Mont, 14(2), 17-19.

Krivokapić, D. (2017). Theories of tiredness in sport. Sport Mont, 15(1), 35-37.

Kuchar, R. (2017). Women, Sport and Baby-is it possible to do/have all?. Sport Mont, 15(2), 21-24.

Ljubojević, M., Muratović, A., \& Bubanja, M. (2016). Effects of various physical education curriculum on motor skills in students of final grades in primary school. Sport Mont, 14(1), 25-28.

Ljubojević, M., Muratović, A., \& Bubanja, M. (2017). Structure of cognitive abilities and skills of lifeguards. Sport Mont, 15(1), 27-29.

Mahmutović, I., Rađo, I., Talović, M., Lakota, R., Alić, H., \& Jelešković, E. (2016). Level of transformation of motor skills in female volleyball players influenced by training operators. Sport Mont, 14(2), 39-43.

Majerič, M. (2016). The importance of sport in students' lives and the frequency of sport participation among students gender differences. Sport Mont, 14(2), 3-6.

Majerič, M. (2016). Gender differences in popularity and engagement in sport activities among students. Sport Mont, 14(3), 31-35.

Martin, V., \& Sæther, S. (2017). Talented High School Football Players' Perception of Talent Identification Criteria. Sport Mont, 15(2), 3-7.

Milašinović, R., \& Popović, S. (2016). Historical development of skiing with special retrospection in Montenegro. Sport Mont, 14(1), 39-41.

Milašinović, R., Popović, S., Matić, R., Gardašević, J., \& Bjelica, D. (2016). Body height and its estimation utilizing arm span measurements in male adolescents from southern region in Montenegro. Sport Mont, 14(2), 21-23.

Milašinović, R., Popović, S., Jakšić, D., Vasiljević, I., \& Bjelica, D. (2016). Body height and its estimation utilizing arm span measurements in female adolescents from southern region in Montenegro. Sport Mont, 14(3), 15-18.

Milašinović, R., \& Bjelica, D. (2017). Historical development of skiing case study in Durmitor area. Sport Mont, 15(1), 39-41.
Milošević, Z., Vuković, J., Maksimović, N., \& Matić, R. (2016). The correlation between physical characteristics and motor skills of female secondary school pupils. Sport Mont, 14(2), 35-38.

Mohammed, M.H.H. \& Choi, H.J. (2017). Effect of an 8-week Judo Course on Muscular Endurance, Trunk Flexibility, and Explosive Strength of Male University Students. Sport Mont, 15(3), 51-53. doi: 10.26773/smj.2017.10.010.

Muratović, A., \& Bojanić, D. (2016). Ranging the results achieved in biomotoric and specific-motoric skills in handball players and non-athletes cadet. Sport Mont, 14(1), 29-31.

Muratović, A., Vasiljević, I., Bojanić, D., \& Ljubojević, M. (2016). Frequency of foot deformity among students of faculty for sport and physical education. Sport Mont, 14(3), $19-20$.

Musalek, M., Kokstejn, J., Papez, P., Jírovec, J., \& Honsová, S. (2017). Relation Between Percent Body Fat and Fundamental Motor Skills in Pre-School Children age 3-6 years. Sport Mont, 15(2), 9-13.

Nerland, E., \& Sæther, A. (2016). Norwegian football academy players-players self-assessed competence, perfectionism, goal orientations and motivational climate. Sport Mont, 14(2), 7-11.

Nová, J. (2017). Utilization of Research for Elite Sport in the Czech Republic. Sport Mont, 15(3), 35-38. doi: 10.26773/smj.2017.10.006.

Oreb, B., Prlenda, N. \& Oreb, G. (2017). Differences between Students of two Different Study Programs in Assessment of Water Sports Teaching Standard. Sport Mont, 15(3), 39-41. doi: $10.26773 / \mathrm{smj} .2017 .10 .007$

Ödek, U. (2016). Comparison of two interpolation methods for resampling center of mass velocity data. Sport Mont, 14(1), 43-44.

Peja, E., \& Tase, E. (2016). Relation of age at menarche to physical activity. Sport Mont, 14(3), 7-10.

Popović, S., \& Milašinović, R. (2016). Model of advertising communication in sport. Sport Mont, 14(1), 33-38.

Popović, S., Šestović, J., Đurović, N., \& Vlahović, S. (2016). Planning network of sports facilities in the context of Montenegro case study: Herceg-Novi, Podgorica and Danilovgrad. Sport Mont, 14(2), 45-51.

Popovic, S., Gardasevic, J., Masanovic, B., Arifi, F. \& Bjelica, D. (2017). Standing Height and its Estimation Utilizing Foot Length Measurements in Adolescents from Western Region in Kosovo. Sport Mont, 15(3), 3-7. doi: 10.26773/ smj.2017.10.001.

Rađo, I., Alić, H., Bajramović, I., Jelešković, E., Ćović, N., Likić, S., \& Mekić, A. (2016). Functional strength training effects on knee flexors and extensors power output in football players. Sport Mont, 14(2), 13-16.

Radas, J., Sesar, V. \& Furjan-Mandic, G. (2017). Differences between Female Subjects Practicing Pilates and Aerobics. Sport Mont, 15(3), 25-28. doi: 10.26773/smj.2017.10.004.

Sermaxhaj, S., Arifi, F. \& Bahtiri, A. (2017). The Effect of Static Stretching in Agility and Isokinetic Force at Football Players. Sport Mont, 15(3), 29-33. doi: 10.26773/smj.2017 .10 .005 .

Siljak, V. \& Djurovic, D. (2017). Historical Development of the Olympic Movement. Sport Mont, 15(3), 43-46. doi: 10.26773/smj.2017.10.008.

Slacanac, K., Baic, M., \& Starcevic, N. (2017). Competition Efficiency Analysis of Croatian Junior Wrestlers in European Championship. Sport Mont, 15(2), 43-47.

Stankovic, M., Peric, D., Ruíz-Llamas, G. \& Quiroga-Escudero, M.E. (2017). Effects of Experimental Volleyball Rules Qu- 
antified by Type and Number of Jumps, Hits and Contacts. Sport Mont, 15(3), 9-16. doi: 10.26773/smj.2017.10.002.

Vasiljević, I., Bjelica, D., Kezunović, M., \& Gardašević, J. (2016). Knowledge of physicial education students on sports nutrition. Sport Mont, 14(1), 17-19.

Vasiljevic, I., Gardasevic, J., Kezunovic, M., \& Bojanic, D. (2017). Waist Circumference as an Indicator Abdominal Obesity in Middle Age. Sport Mont, 2017, 15(1), 21-22.

Vujkov, S., Calals, C., Krneta, Ž., \& Drid, P. (2016). Ultra short-term heart rate recovery after maximal exercise in two different body positions in elite male judokas compared to students of the sport faculty. Sport Mont, 14(1), 7-11.

Zemková, E., Jeleň, M., Zapletalová, L. \& Hamar, D. (2017). Muscle Power during Standing and Seated Trunk Rotations with Different Weights. Sport Mont, 15(3), 17-23. doi: 10.26773/smj.2017.10.003.

Zvonar, M., Vavacek, M., \& Cierna, D. (2016). Temperature changes on the foot during pregnancy affected by wearing biomechanical shoes. Sport Mont, 14(1), 3-6.

\section{M.Maros}

University of Montenegro, Faculty for Sport and Physical Education, Narodne omladine bb, 81400 Niksic, Montenegro e-mail:miomirm@ac.me 